\title{
More than Increased Numbers: A Mentoring Program for Females in Science and Engineering
}

\section{Lisa Carlson, South Dakota School of Mines and Technology}

Lisa Carlson is the Director for Women in Science and Engineering at South Dakota School of Mines and Technology. Ms. Carlson earned her Bachelor of Science in Business Administration- Marketing, at Black Hills State University, and her Master of Business Administration at Chadron State College. Working mainly with women's issues at the university, Ms. Carlson established a women's mentoring program for all first year students and recently established a women's center - the first of its kind on any South Dakota university campus.

\section{Dr. Shaobo Huang, South Dakota School of Mines and Technology}

Dr. Shaobo Huang is an Assistant Professor and the Stensaas Endowed STEM Chair in the Department of Mechanical Engineering at South Dakota School of Mines \& Technology. Her research interests include student retention and academic performance in engineering, student achievement evaluation and assessment, and K-12 STEM curriculum design.

\section{Dr. Cassandra M Degen, South Dakota School of Mines and Technology}

Dr. Cassandra Degen received her B.S. degree in Metallurgical Engineering from the South Dakota School of Mines and Technology in 2007. She received her Ph.D. in Materials Science and Engineering in 2012 from the University of Illinois at Urbana-Champaign, studying mechanochemical reactions of a spiropyran mechanophore in polymeric materials under shear loading. She is currently an Assistant Professor in the Mechanical Engineering department at the South Dakota School of Mines and Technology where her research interests include novel manufacturing and characterization techniques of polymer and composite structures and the incorporation of multifunctionality by inducing desired responses to mechanical loading.

Sarah Folsland, Woment in Science and Engineering 


\section{More than increased numbers: A mentoring program for the females in science and engineering}

\section{Introduction}

The concerns of low numbers of women in STEM have led to studies on the attrition ${ }^{1}$ and the implementations of programs for the female students ${ }^{2}$. Studies found that students who withdraw from STEM majors are less involved in extra-curricular engineering activities, have lower engineering self-efficacy and career expectations, but higher anxiety ${ }^{1,3}$. However, the average GPA of women who withdraw from STEM is no different than that of others ${ }^{1}$. To increase the retention of women in STEM, solutions have been proposed by many studies such as facilitating communities for females ${ }^{4-5}$, involving peer mentors ${ }^{6-9}$, and mentoring by faculty and/or women engineers ${ }^{10}$.

According to the American Association of University Women ${ }^{11}$ (AAUW), women in science and technology often attribute their success to the core relationship they developed with a mentor, and mentoring has been shown to be especially beneficial to girls and women of color, who must struggle through race and gender barriers to science and math fields. AAUW has conducted research showing that employees who received mentoring, either academically or professionally, were promoted five times more often than people who didn't have mentors. Additionally, a research study by Sun Microsystems showed that mentors themselves were six times more likely to be promoted.

The Women in Science and Engineering (WiSE) program at South Dakota School of Mines \& Technology (referred to as SDSM\&T) provides students, with particular emphasis on women, support, encouragement, and information intended to help them stay in STEM fields. WiSE is taking the lead role on campus to support the academic and professional success of women. WiSE is a comprehensive, campus-wide program that encompasses support for women students through professional development, networking, and outreach opportunities. Under the WiSE umbrella, the program offers students monthly programming through its "STEMinist Speaker Series," which features alumni and industry speakers. Other programming offered includes professional and career development, the mentoring program, weekly study sessions in the WiSE Center called "STEMinist Study Hall," opportunities for students to get involved with outreach to K-12 girls, and collaborative opportunities for student and faculty peers.

Under the WiSE umbrella program, the WiSE Center and mentoring program are catalysts to enable the campus to further develop and engage our community and industry partnerships. WiSE allows SDSM\&T to connect with similar organizations who share our goal of student success for women.

\section{Mechanical Engineering Efforts to Increase Female Enrollment Recognized}

The WiSE program in its current form originated out of the Mechanical Engineering program after the department saw significant success in its methods to recruit and retain women students. In 2011, the Mechanical Engineering (ME) department began efforts to increase enrollment in 
women. The focus of this recruitment effort was diversity, particularly the recruitment of women to that particular program. Aligning with the goal, the following objectives were developed.

Objective 1: Increase the enrollment and retention of the female engineering students.

Objective 2: Improve female students' attitudes and perceptions toward careers in engineering fields.

Objective 3: Enhance female students' self-efficacy in the learning of engineering.

Objective 4: Increase the six-year graduation rate of female students (currently at $53 \%$ for the university). The department placed an emphasis on increasing the general graduation rate of all women students as opposed to just women engineering students to be aligned with the university's strategic goals.

In alignment with these objectives, from 2011 to 2014, the ME department implemented a series of comprehensive recruitment and retention tactics. First, the department implemented measures to bring more engineering career exposure to young women ${ }^{12}$, group women students together to provide lateral support ${ }^{8}$, and, working with NSF through a grant called the Culture and Attitude Scholarship (C\&A) program, provide scholarship funds to those with financial need. The C\&A program is a multi-disciplinary program that seeks to increase the enrollment of mechanical, industrial, and metallurgical engineering women students through scholarship funds, informal mentorship, and programming. Additionally, the department initiated a comprehensive women's mentoring program in the fall of 2012 for women students only. This program partnered entering freshmen with a current female student (sophomore-senior) to informally mentor them, and mentors/mentees formed a cohort of one mentor to a minimum of three mentees. The initial goal of the Mentoring Program within the Mechanical Engineering department was to increase both enrollment and recruitment of women. The department mentoring program produced an overall undergraduate enrollment of 615 students as of Fall 2013 (a 54\% increase over the Fall 2010), with an overall women undergraduate enrollment of fifty-six students (a 100\% increase over the Fall 2010).

The total percentage of women in the Mechanical Engineering department is given in the far right column of Figure 1 below. Since 2010, the percentage of women freshmen has steadily increased. In addition, the freshmen to sophomore retention decreased from $2010-2012$ and increased significantly in 2013. We attribute this increase in retention to the rising of the first class of women freshmen who participated in the Mentoring Program in 2012 to their sophomore year. Data from 2013 is used to show the increase in women enrollment during the academic years during which the recruitment activity for women students occurred. 


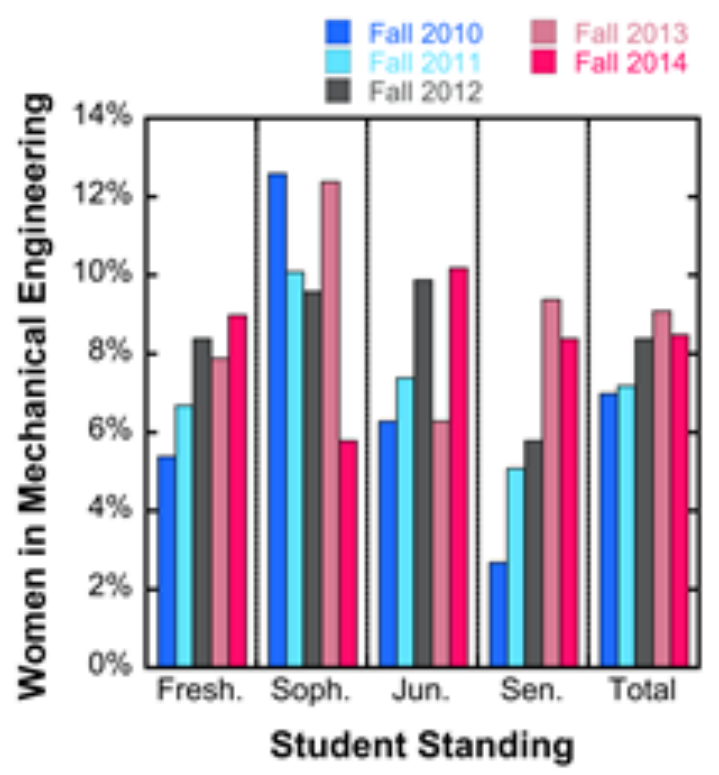

Figure 1. Percentage of women students in ME department

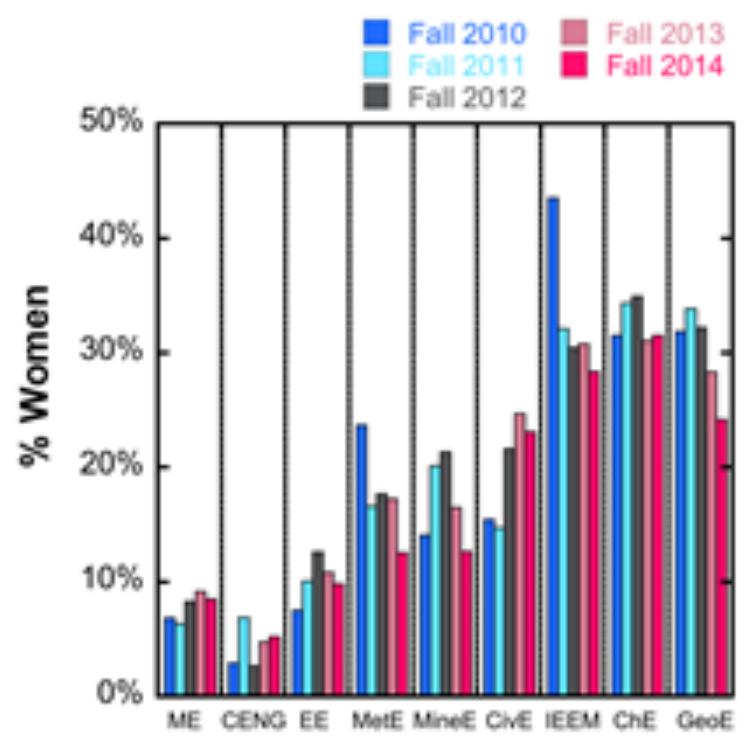

Figure 2. Percentage of women students on campus

An additional testament to the effectiveness of the Mechanical Engineering Mentoring Program is the increase in enrollment and retention in the Mechanical Engineering department as compared to other departments on campus. Figure 2 shows the percentage of women in various departments across campus from 2010 - 2014. The departments listed are Mechanical Engineering (ME), Computer Engineering (CENG), Electrical Engineering (EE), Metallurgical and Materials Engineering (MetE), Mining Engineering (MineE), Civil Engineering (CivE), Industrial Engineering and Engineering Management (IEEM), Chemical Engineering (ChE), and Geological Engineering (GeoE). While Mechanical Engineering has one of the lowest percentages of women students across campus, we are only one of two (with Civil Engineering) to steadily increase the percentage of women since 2010. Mechanical Engineering in particular is a traditionally male-dominated field and has one of the lowest percentages of women on the SDSM\&T campus. The initial implementation of the Mentoring Program was in the Mechanical Engineering department for this reason.

\section{Emulating ME Success Through a Campus-Wide Platform}

Because of the success with efforts aimed at recruiting and retaining women students, the university administration asked Ms. Carlson, who was overseeing the Mechanical Engineering department's efforts to recruit and mentor women students, to re-launch the WiSE program campus-wide in 2013, in order to emulate ME's success for all women students in all disciplines. The program has expanded since its re-launch to be an extremely robust support mechanism for all current women students on campus, with an outreach arm as well as significant efforts in recruiting women students. WiSE offers our STEMinists, as we like to call them, a host of monthly and annual events, including formal mentoring for all first-year women students, 
informal mentoring throughout the remainder of their academic career, career exploration and planning $^{12}$, access to professional development opportunities and professional conferences, and outreach opportunities $^{13}$.

WiSE staff, with the direction and leadership of the steering committee, creates the programming. The program is developed with leadership and direction from a steering committee consisting of students from engineering and science disciplines, faculty members from engineering and science disciplines, student support service administrators, the director, and the program coordinator. The program addresses challenges faced by women in entering STEM fields, graduating and staying in STEM professions, and advancing to corporate leadership roles.

WiSE receives approximately $\$ 9,700$ in state funding through the university. In addition, the program seeks external funding, through the university foundation, to supplement its budget in order to offer programming, stock the WiSE Center with resources and supplies, fund outreach and recruitment efforts, and to fund the mentoring program. Along with 26-30 peer mentors, there is one full-time WiSE staff, director Lisa Carlson, and one part-time employee, coordinator Sarah Folsland.

\section{WiSE Mentoring Program: An Integral Program Component}

Although WiSE is a comprehensive support mechanism for women students involving several different components, one of its most effective and grassroots concepts is its peer mentoring program. In 2014, the administration asked Ms. Carlson to expand the successful Mechanical Engineering mentoring program campus-wide through the WiSE program, to include all science and engineering disciplines. The campus-wide WiSE mentoring program consists of five primary, interactive components: first-year women students as mentees, peer mentors, department faculty points of contact, WiSE staff (director and coordinator), and social support component.

The campus-wide women's mentoring program within WiSE pairs first-year, degree-seeking women students with upper-class women students in similar disciplines. All first-year women students are automatically placed in the program; mentors are selected through a self-nomination and application process. The mentors often help their first-year mentees choose classes, prepare for finals, integrate into campus life, and find their way around the local area. The peermentoring program is a fun and rewarding way for first-year students to make a smooth transition from high school to college, including making friends, getting connected to resources, and becoming part of the university and community. In addition to one-on-one communication, mentors and mentees participate in several small-group meetings and scheduled workshops throughout the year. It is an opportunity for first-year students to learn from someone who has "been there, done that."

Along with department faculty points of contact, WiSE staff selects mentors through an application process based on a minimum GPA requirement (3.25 for juniors and seniors, and 3.5 for sophomores) as well as extra- and co-curricular involvement. Selected mentors are paid a stipend of $\$ 500$ per semester and oversee a mentoring cohort of 5-7 mentees. As part of their 
expectations, they are required to attend formal training at the beginning of the year. This training lasts approximately three to four hours, and includes topics on connecting with mentees and communication methods, understanding Title IX and sexual harassment, understanding the mentor-mentee relationship, and helping mentees navigate the home-to-college transition. Mentors are also expected to participate in professional development activities with their mentees, and have meaningful contacts twice a month with each individual mentee and once a month in mentee cohorts.

Each academic department has its own point of contact responsible for administering that department's mentoring program. Points of contact are either faculty or staff members, and are predominantly women faculty. Points of contact are expected to meet with their department's mentors to "debrief" once a month, as well as to organize mentor/mentee professional development activities. WiSE also provides mentor/mentee events on a campus-wide level. There are three components of WiSE: networking, professional development, and outreach, illustrated through monthly activities and yearly events (Figure 3).

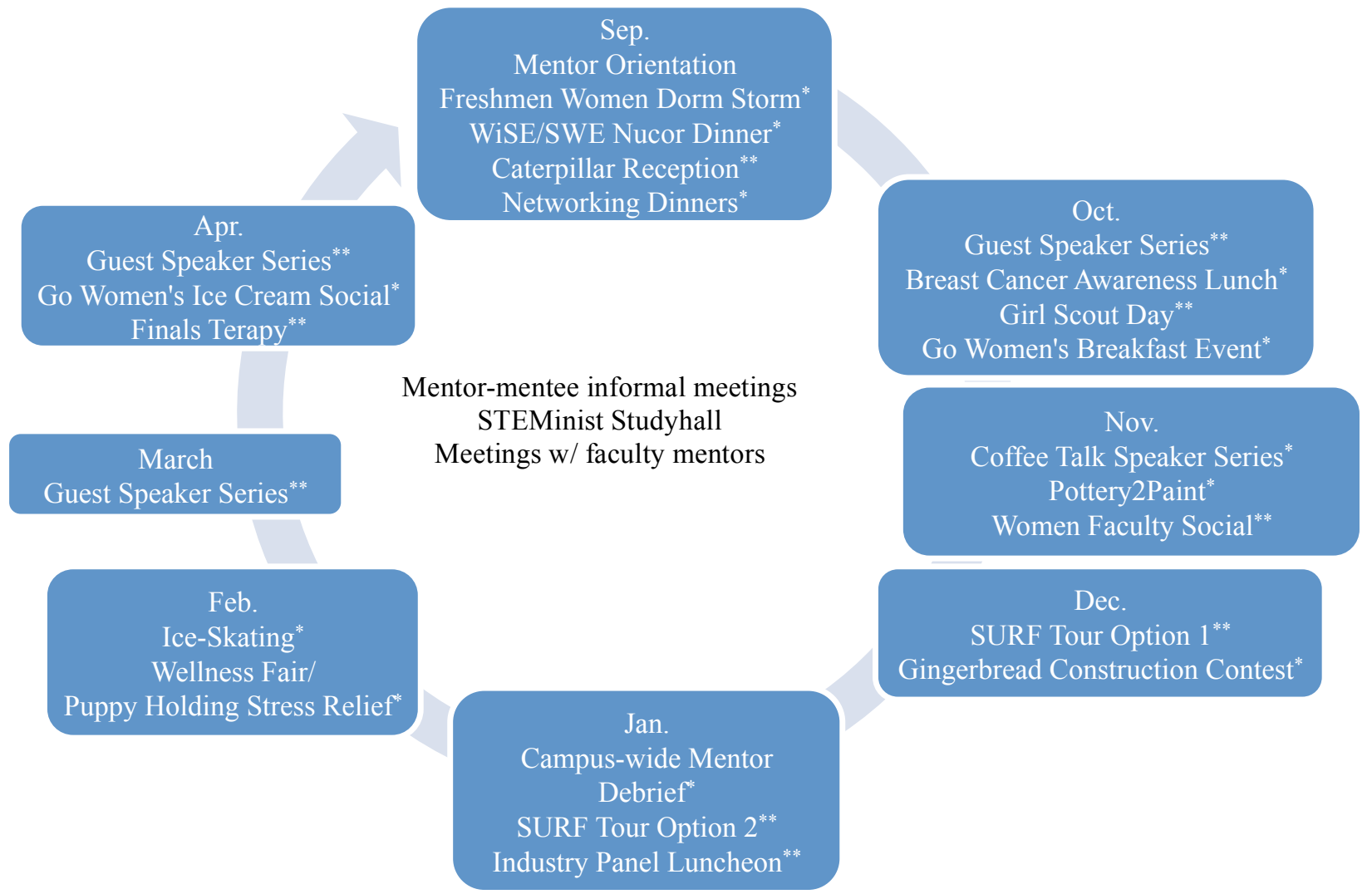

Figure 3. WiSE program activities for 2014-2015 academic year

*Networking

${ }^{* *}$ Professional Development

${ }^{* * *}$ Outreach

Networking: The goal is to connect students with peers, faculty, industry professionals, and women alumni through the peer mentoring program, mentor-mentee events, and monthly programming. The mentoring program groups all first-year women students in cohorts with an 
upper-class peer mentor, who engages them in various campus communities. WiSE staff, with the direction and leadership of the steering committee, creates the programming.

Professional Development: Professional development is offered through coffee talks, alumni and industry speakers, and panel sessions. Professional development and networking events connect current students and help women form meaningful connections with fellow women students, alumni, and valuable industry contacts.

Outreach: Student have an opportunity to engage K-12 students and prospective women students during outreach opportunities throughout the year; and developing partnerships with Girl Scouts and other local groups.

WiSE takes special care to collaborate with several other programs across campus. The Society of Women Engineers, Alpha Delta Epsilon sorority, and Alpha Delta Pi sorority partner heavily with WiSE on different events throughout the year. In addition to student groups, WiSE collaborates often with the Office of Multicultural Affairs, the Career and Professional Development Center, the Student Activities and Leadership Center, the Veteran's Center, the Culture and Attitude Scholarship program, departmental faculty, and co-curricular organizations in order to maximize resources, student involvement, and faculty integration.

Students benefited from these events both in professional and career development as well as social and networking skills. One year into the mentoring program as a campus-wide initiative, first time freshmen women's retention held steady at $81 \%$ while retention for men dropped from $76 \%$ to $74 \%$. Enrollment for first time freshmen women students, which had been down fall 2014 , increased by over $8 \%$ for fall 2015 . The program addresses challenges faced by women in entering STEM fields, graduating and staying in STEM professions, and advancing to corporate leadership roles.

\section{Mentoring Program Assessment}

This section assesses the impact of the WiSE program on women students' learning of engineering majors. It has two foci: mentor/mentees' engineering self-efficacy and their perceptions toward the mentoring program. Both quantitative and qualitative data were collected from the women students (both mentors and mentees) participating in the WiSE program between fall 2014 and fall 2015.

\section{Assessment results}

Demographic: A total of 34 mentees and 24 mentors in fall 2014; while 51 mentees and 23 mentors in fall 2015 were involved in the study. The majority of the mentees $(100 \%$ in 2014 and $80 \%$ in 2015 ) were in the same department as their mentors. Twelve (35.3\%) mentees in fall 2014 and 4 (7.8\%) in 2015 were transfer students or had a full-time job before they enrolled in SDSM\&T. All mentees were enrolled as full-time students and approximately $85 \%$ of them were taking 5 or more courses in the semesters when they responded to the surveys. The parents of 7 $(20.6 \%)$ mentees in 2014 and $4(7.8 \%)$ in 2015 did not have post-secondary or higher education. Ten (29.4\%) mentees in 2014 and $13(25.5 \%)$ in 2015 had at least one parent working as an engineer or scientist. The data were consistent with the findings from other studies that parents' 
characteristics were not significant indicators of students' attitudes toward STEM disciplines at college ${ }^{1}$.

Interactions with the WiSE program: Student attendance at the WiSE events, such as group studying and co-/extra-curricular activities, as well as other traditional events on campus were surveyed. As shown in the Figure 4, the co-/extra-curricular activities were well received by the mentees and mentors. Overall, more than 74\% mentees and mentors attended the WiSE organized co-/extra-curricular activities at least once per month. Many mentees and mentors liked the Group Studying activity because it provided a "private and safe" space for them to study and/or discuss.

All mentees were actively involved in the peer mentoring program and approximately $40 \%$ mentees met with their mentors more than three times per semester besides during the

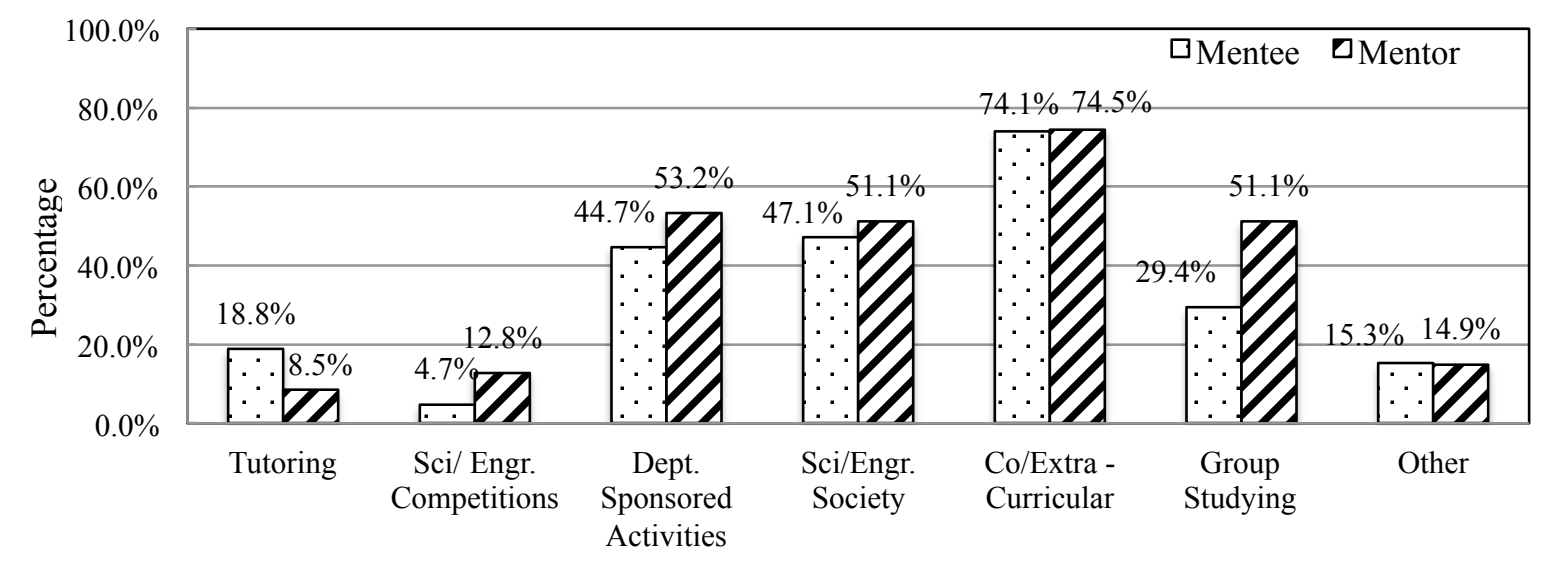

Figure 4. Percentage of mentees who attend an activity once per month.

mentor/mentee activities organized by the WiSE program. Over $45 \%$ of the mentees kept an informal mentoring relationship with their former mentors if they were assigned to a different mentor in the second year in the WiSE program. The mentees felt "they are someone who can talk to you and share their experiences to help you" and "both my mentors are super encouraging, and have great insight into what I need to do to attain my personal goals."

Data analyses in both fall 2014 and 2015 indicate the WiSE events had significant impacts over students' attitudes. For example, the mentees who attended WiSE events at least once per month in fall 2015 had higher career expectation $\left(t_{49}=2.04, p<0.05\right.$, Cohen's $\left.d=0.58\right)$ and mathematics expectation ( $t_{49}=2.28, p<.05$, Cohen's $\left.d=0.65\right)$ than those who did not. Cohen's $d$ is employed in this study to assess the effect sizes of the program. Cohen's $d$ s ranging from 0.5 to 0.7 indicate medium effect sizes ${ }^{14}$ of the program on mentees' career and mathematics expectations.

Mentees' perceptions: A set of 6-point Likert scale questions was adapted from CCTS Mentor Evaluation $^{15}$ to investigate students' perceptions of the mentoring program in terms of intellectual growth, professional development, academic guidance, personal communication, and serve as role model. 
As shown in Figure 5, the means of students' perceptions of the mentoring group in fall 2015 was higher than those in fall 2014. We provide two primary reasons. First, many mentors in fall 2015 were first involved in the program as mentees; while those in fall 2014 were not. The mentors in fall 2015 gained a better understanding of the mentoring program by experiencing it as mentees. This indicates the importance of appropriate trainings on mentoring skills and strategies for the mentors. Furthermore, feedback on WiSE events/activities was well addressed in the next semester which significantly improved mentees' ratings over the program in fall 2015. For example, in responding to the question "What is hard about having a mentor", 11 out of 29 responses indicated "finding a good time to meet between each other's schedules" was challenging; while 7 mentees felt "nervous" to contact their mentors. Most mentees and mentors suggested earlier and more group meetings to improve the mentoring program:

"Meeting your mentor sooner instead of half way through the semester."

"More often (and earlier) mentor + mentee events."

"More set times on group meetings."

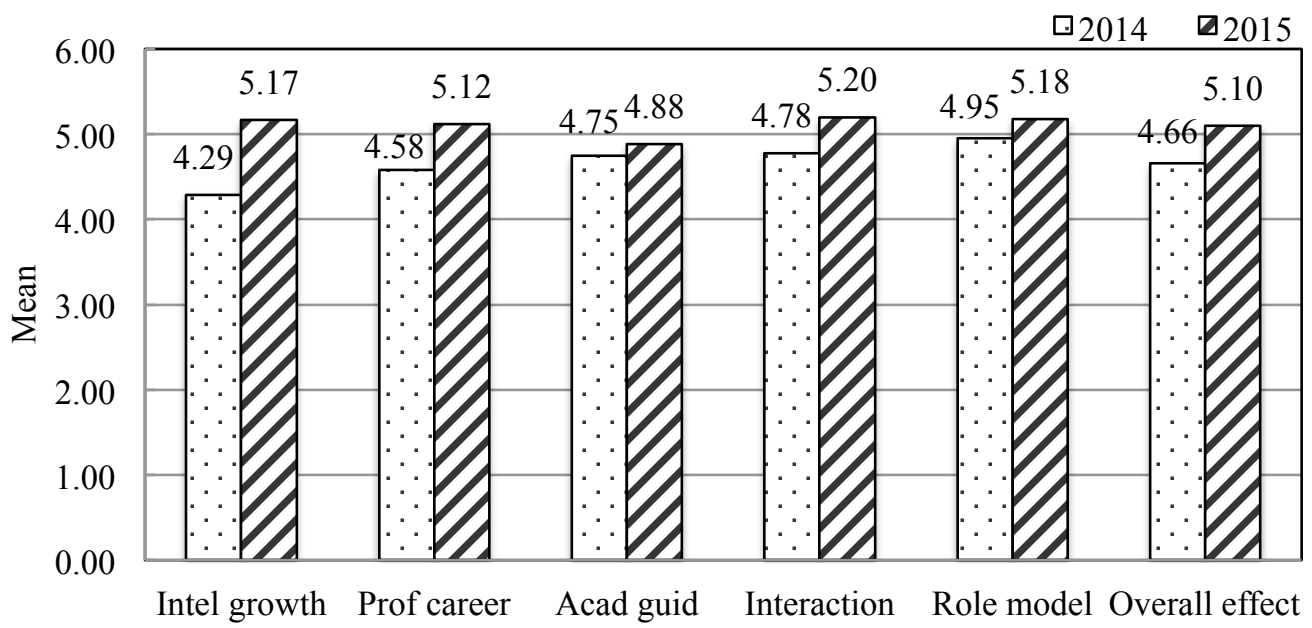

Figure 5. Mentees' perceptions of the mentoring program

To help the mentees have an easier transition to college, some changes were made to the program in the fall of 2015. All mentors now visit their mentees in their dorms during the first week of the semester to initiate the mentoring relationship and get familiar with their mentees. More group activities were designed in 2015, such as the adventure weekend.

"... Many of the incoming freshman may not understand the full intentions of the program. I know many of my mentees said the adventure weekend really helped them see the benefits of having a mentor and that it doesn't have to always be all work and no play. They were glad they attended even though at first they didn't really want to go..."

Furthermore, mentees who attended the WiSE events at least once per month perceived significantly higher intellectual growth $\left(t_{49}=2.45, p<.05\right.$, Cohen's $\left.d=0.72\right)$ and professional development $\left(t_{49}=2.46, p<.05\right.$, Cohen's $\left.d=0.74\right)$. The Cohen's ds indicate medium to large ${ }^{14}$ effect on the mentees' intellectual growth and professional development. 
Engineering self-efficacy: The instrument Longitudinal Assessment of Engineering SelfEfficacy $^{16}$ (LAESE), a 6-pionts Likert scale survey, was adapted for this study. Figures 6 and 7 show the results of mentees and mentors' feeling of inclusion, engineering self-efficacy, mathematics expectation, career expectation, and coping assessed in the fall 2014 and the fall 2015. On average, the mentees had a relatively lower feeling of inclusion, engineering selfefficacy, and career expectation; however, higher mathematics expectation than mentors. Generally, high school women graduates enroll in a STEM major with high confidence in mathematics. This confidence can decrease in the first two years in college because of advanced mathematics courses, such as calculus, linear algebra, and/or differential equations. The mentees had a significant increase in career expectations in the fall 2015. It is believed that WiSE events such as a networking dinner with women engineers and scientists and the guest speaker lectures/communications have significantly inspired women students' career awareness and expectations. No statistically significant differences were found in the mentors' self-efficacy from 2014 to 2015 academic year.

Longitudinal data will be collected to investigate the causal relationships promoted by the events provided by the WiSE program and students' changes in engineering self-efficacy and perceptions of the program.

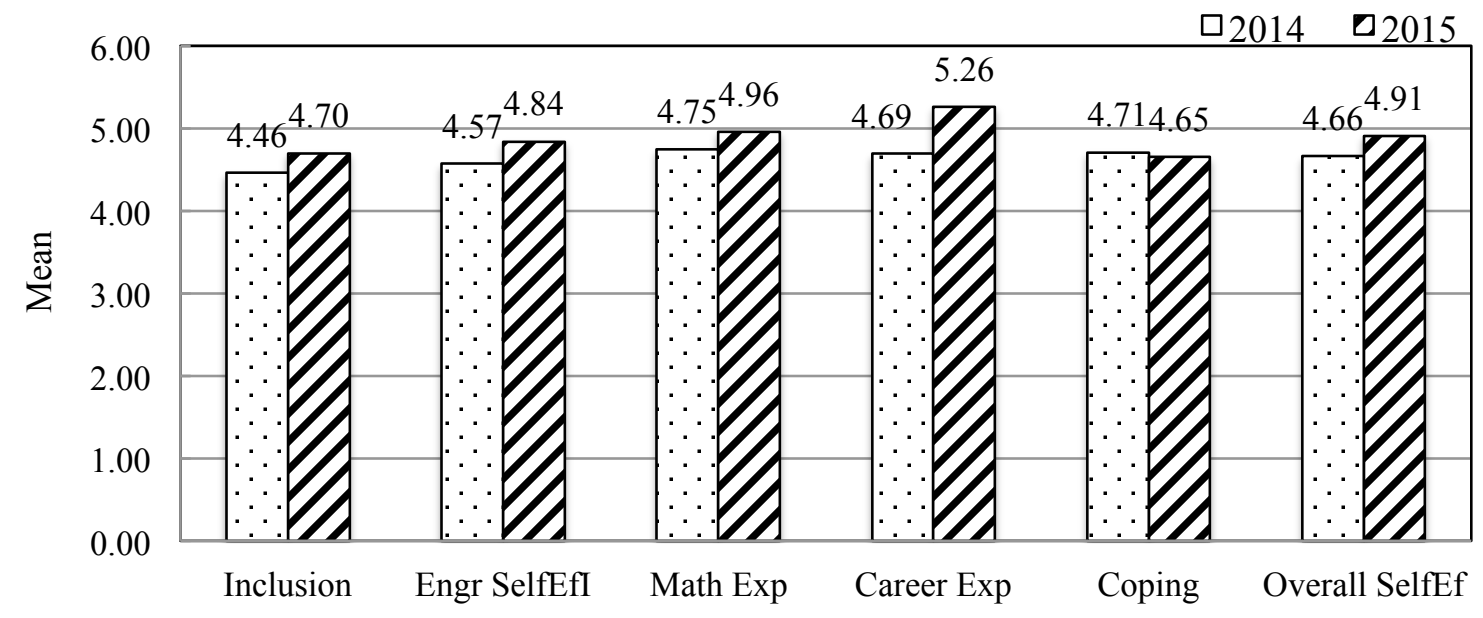

Figure 6. Mentees' engineering self-efficacy 


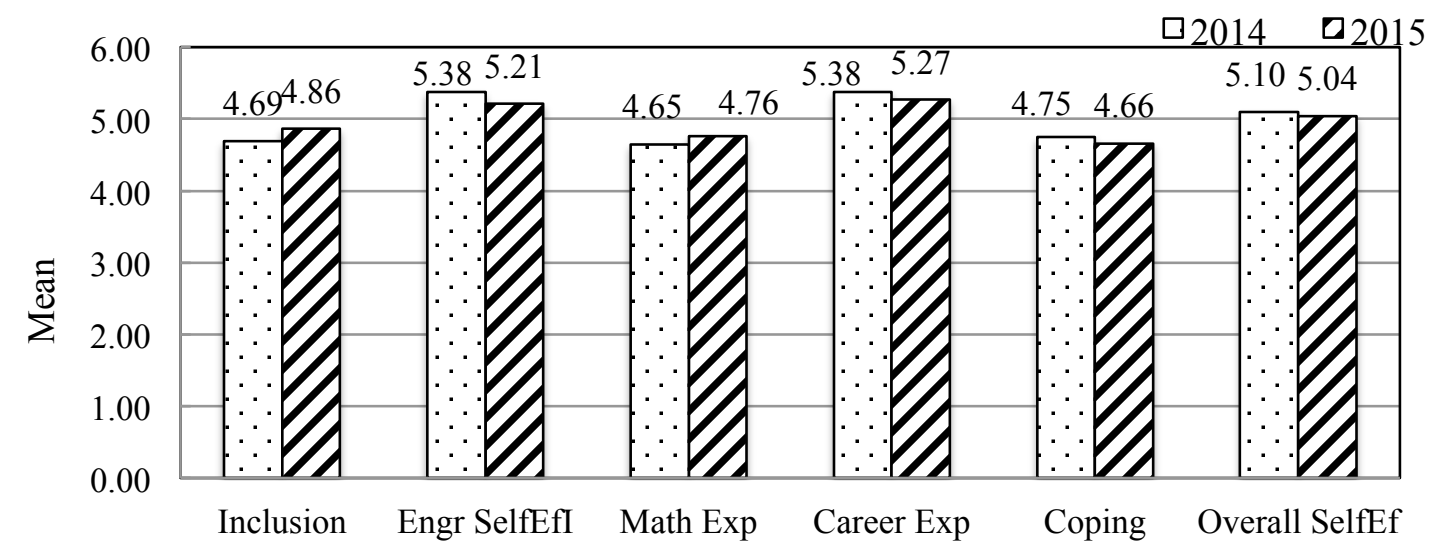

Figure 7. Mentors' engineering self-efficacy

\section{Future Work: The Women in Science and Engineering Center}

Constructive feedback from women students in the last five years included a strong desire for a physical space on campus devoted to helping women students find resources and study. Students felt that a dedicated space would provide increased opportunities for student collaboration and a gathering place where female students can study, participate in team-based learning, and network with other students and faculty. In the fall of 2015, those comments came to fruition with the opening of the WiSE Center, the first of its kind among the XX Board of Regent schools. The long-term goals of the center are:

- to connect isolated areas of efforts in women in science and engineering to other programs,

- to create relationships among organizations through women of various ages and roles, all centered on STEM and service to the community,

- to increase enrollment of women students at SDSM\&T to $27 \%$ by 2020 (currently at $\sim 23 \%$ ),

- to increase retention of first time freshmen women students to $85 \%$ by 2020 (currently at $81 \%$ ), and

- to increase self-efficacy, motivation, and persistence of women students to graduate in STEM (science, technology, engineering, and math) degrees.

The indirect goals include:

- Recruit a higher number of women high school seniors into engineering and science majors

- Retain academically motivated women students that are committed to an engineering or science career

- Educate a wider breadth of girls and young women about STEM fields

The center exists to help every woman student at SDSM\&T succeed by providing opportunities for actively engaging in the world through leadership, professional development, outreach, and activism. The center does not discriminate toward gender and welcomes all gender identities who are committed to gender inclusion and helping to champion women in STEM fields. 
Since its inception, the center has promoted gender inclusion through co-curricular programming and advocating on gender issues throughout the university and community. The center's primary focus is service, support, and resources to undergraduate and graduate students.

The center promotes academic and professional success for our female students, who use the space as a gathering place to stop in between classes, study, have coffee, find resources, meet in mentoring cohorts, attend small events, or use the printer, refrigerator or microwave. WiSE staff also utilizes the space as a tool to help recruit prospective women students, in collaboration with the Admissions department.

In addition to being a resource for students, the center also provides a venue for continued collaboration and networking with national industry partners such as Kiewit, Nucor, and Caterpillar. These partners hire SDSM\&T graduates, have female representation on academic advisory boards, and provide input on curriculum. Women engineers and scientists in the local community are invited to program events with students and have the opportunity to serve as industry mentors. WiSE has ties to local civic organizations and collaborates frequently with local industrial partners.

To address program goals, WiSE staff has designed activities for 2016 to promote the interactions between students, faculty, and industry mentors. Here is an example of this semester's programming:

WiSE Coffee Talk Speaker Series: Dr. Pritchard

Description: Passive or Polite: how to say what you mean to get what you want. You'll leave with a caffeine high and insights about how your gender may be influencing your communication.

\section{WiSE Forum}

Description: Get the scoop on life in the real world. Ask questions at our panel discussion featuring women from Boeing, Caterpillar Inc., Maptek, National Guard, and the Black Hills Surgical Hospital.

\section{WiSE Snowshoeing \& S'mores}

Description: WiSE mentors and mentees will head to the Outdoor Campus for a guided snowshoeing adventure followed by a bonfire and s'mores.

\section{WiSE Speaker Series: Sharlissa Moore}

Description: Where can the science pipeline take you? Your STEM background is your ticket to choose your own adventure. Hear from Sharlissa Moore about how her undergraduate studies in astronomy and physics led her to research solar energy in North Africa, impact policy at the White House, and publish work about sustainable development. Dr. Moore teaches Human and Social Dimensions of Science and Technology at Arizona State University. She'll offer career advice and a new perspective about where your education and research can lead.

\section{The Brain Scoop with Emily Graslie}


Description: Emily is the Chief Curiosity Correspondent at Chicago's Field Museum of Natural History. Her YouTube Channel "The Brain Scoop" is listed as one of the New Media Rockstars and has been featured on The Huffington Post, New York Times, National Public Radio, Scientific American, and the Chicago Sun-Times to name a few. Join Emily for a discussion about women in STEM fields.

\section{Women in Science Conference}

Description: Want to beef up your resume and act as a role model for budding STEMinists? Women in Science is a free, one-day career learning workshop designed to provide young women in grades 6-12 with engaging opportunities to learn about STEM careers, and we're looking for student, staff, and faculty volunteers. Last year 15 schools and 500 students attended the conference, with attendance this year anticipated to be over 600 .

Generations Inc., Managing the friction between generations in the workplace Description: Meagan Johnson speaks to audiences all over the world on how they can manage and motivate different generations in the workforce. Join WiSE and Black Hills Corporation's women's leadership initiative, ASPIRE, for a reception and hear from Johnson about how to succeed in the workforce.

WiSE Speaker Series: Connie Determan

Description: Connie is Vice Present at Kiewit. Join us for a discussion with Connie and gain insight from her highly successful career.

WiSE Finals Therapy

Description: Reduce your stress and cuddle with a puppy in Surbeck. Then hit the books in the WiSE Center with study snacks and tutors.

\section{STEMinist Studyhall}

Description: Study with your fellow STEMinists each Thursday evening. Snacks provided.

\section{WiSE Birthday Bash}

Description: Join us for a campus wide birthday party each month. Cupcakes. Yum.

\section{Conclusion}

The WiSE program has evolved to be a very robust support mechanism for under-represented groups on campus and will continue to strive to address student concerns and implement campus climate change through its programming and support initiatives. We will continue to build relationships with industrial and community partners to bring greater awareness to campus initiatives. Through these partnerships, we can form a "village" of partners in order to train up well-rounded STEMinists, engineers and scientists that will go forward and do meaningful work, and most importantly, will hold wide open the door for future women students to engage in STEM careers. 


\section{References}

1. Hartman, H., \& Hartman, M. (2006). Leaving engineering: Lessons from Rowan University's college of engineering. Journal of Engineering Education,95(1), 49-61.

2. Bottomley, L. (2015). Assessing the Success of Programs for Women in Engineering. Proceedings of American Society for Engineering Education. Seattle.

3. Felder, R. M., Felder, G. N., Mauney, M., Hamrin, C. E., \& Dietz, E. J. (1995). A longitudinal study of engineering student performance and retention. III. Gender differences in student performance and attitudes. Journal of Engineering Education, 84(2), 151-163.

4. Goodman, I. F. (2002). Final Report of the Women's Experiences in College Engineering (WECE) Project. Online Submission. Retrieved at http://files.eric.ed.gov/fulltext/ED507395.pdf

5. Bottomley, L., Titus-Becker, K., \& Smolensky-Lewis, H. (2009). ESCape to Engineering: A Summer Bridge Program for Women in Engineering. Proceedings of American Society for Engineering Education.

6. Attarzadeh, F., Gurkan, D., Moges, M. A., Ramos, M. A., Gallardo, V. J., \& Mehrubeoglu, M. (2011). NSF Grantee Presentation: Challenges Of Implementing A Peer Mentoring Program To Support Stem Learning. Proceedings of American Society for Engineering Education.

7. Johnson, J., Niemi, A. D., Gree, M. G., \& Gentry, L. E. (2014). Management and Assessment of a Successful Peer Mentor Program for In- creasing Freshmen Retention. Proceedings of American Society for Engineering Education. Indianapolis.

8. Perez-Castilleos, R, \& Santhanam, P. R. (2014). Student-led Mentoring Program Fostering Retention of Female Undergraduate Students in STEM Fields. Proceedings of American Society for Engineering Education. Indianapolis.

9. Clark, J. I., Godd, S. L., Des Jardins, A. C., Foreman, C. M., Gunnink, B. W., Plumb, C., \& Stocker, K. R. (2015). Peer Mentoring Program: Providing early intervention and support to improve retention and success of women in engineering, computer science, and physics. Proceedings of American Society for Engineering Education. Seattle.

10. Kim, D. L., Lee, Y. H., \& Oh, M. S. (2012). Effect of Women in Engineering Programs on the Retention of Female Engineering Students. Presented at the Inaugural International Forum, Proceedings of American Society for Engineering Education. San Antonio.

11. AAUW (2013). Global Issues Leadership Programs. Retrieved at http://www.aauw.org/article/aauw-launchesnew-online-mentoring-program/

12. Ganster, K. J. (2006). " Women in Engineering... A Winning Combination" Program. Women in Engineering ProActive Network.

13. Fletcher, S. L., Newell, D. C., Newton, L. D., \& Anderson-Rowland, M. R. (2001). The WISE summer bridge program: Assessing student attrition, retention, and program effectiveness. In Proceedings, American Society for Engineering Education.

14. Rice, M. E., \& Harris, G. T. (2005). Comparing effect sizes in follow-up studies: ROC Area, Cohen's d, and r. Law and human behavior, 29(5), 615.

15. CCTS mentor Evaluation Form, Retrieved at https://mentoringresources.ictr.wisc.edu

16. Marra, R. M., Rodgers, K. A., Shen, D., \& Bogue, B. (2009). Women Engineering Students and Self-Efficacy: A Multi-Year, Multi-Institution Study of Women Engineering Student Self-Efficacy. Journal of Engineering Education, 98(1), 27-38. 